\title{
Quantifying the Robustness of Countries' Competitiveness by Network-Based Methods
}

\author{
Ming-Yang Zhou $\mathbb{D}$, Xiao-Yu Li $\mathbb{D}$, Wen-Man Xiong, and Hao Liao $\mathbb{D}$ \\ Guangdong Province Key Laboratory of Popular High Performance Computers, College of Computer Science and Software Engineering, \\ Shenzhen University, Shenzhen 518060, China \\ Correspondence should be addressed to Hao Liao; jamesliao520@gmail.com
}

Received 17 May 2018; Accepted 1 November 2018; Published 2 December 2018

Guest Editor: Claudio Tessone

Copyright (c) 2018 Ming-Yang Zhou et al. This is an open access article distributed under the Creative Commons Attribution License, which permits unrestricted use, distribution, and reproduction in any medium, provided the original work is properly cited.

\begin{abstract}
In economic researches, much effort was devoted to the problem of how to increase the economics of countries. However, the development of a country may fluctuate a lot due to international and domestic problems. Thus, we should also evaluate the robustness of countries against unexpected economic recessions. In this paper, we use perturbation to quantify the robustness of countries using two renowned algorithms: method of reflections (MR) and fitness-complexity method (FCM). The robustness characterizes the stability of countries' competitiveness against economic recessions. The experiments in the international trade networks show that FCM could characterize the robustness better than MR. High fitness countries of FCM have strong robustness against economic crises, which enlarges the application fields of FCM. Additionally, we simulate the trade conflict between USA and China. The simulation results show that China suffers much in the trade conflict, while USA loses very little and has strong robustness in this conflict.
\end{abstract}

\section{Introduction}

In network science, the development of a country is assessed by the amount of its imported and exported products. Recent works developed methods to unveil the underlying factors that drive the economic growth of countries based solely on the international trade network [1-4]. As nowadays the economic relationship between countries is strong, an economic depression that starts from one country may largely influence other countries, which may lead to economic crisis and recessions in the whole world. Thus, apart from the assessment of the economic growth of countries, an important feature of countries to consider is their robustness against various economic recessions. However, a new problem arises: would the increase of robustness lead to a decrease of economic growth? Studies show that developed countries should focus on some high-tech and profitable products $[3,5]$, since the high-tech products help maintain and improve their competitiveness. However, unexpected tariff protectionism and natural disasters may deeply influence the exports of some targeted products $[6,7]$. Then, in order to protect against this, a country should diversify its production $[1$,
8]. This is against the classical specialization theory $[3,5]$. Consequently, the relationship between robustness and the competitiveness of countries should be investigated.

Measuring the competitiveness of countries usually requires the detailed industrial data $[9,10]$. However, in recent years, network-based methods provide a simplification of this $[8,11]$. In network-based methods, the only required information is the amount of exports for each country-product pair. If a country is competitive enough in the export of a product, a link is created in the network between the country and the product. The resulting network is the country-product bipartite network. There are two main network-based methods to investigate the countries performance: (1) the method of reflections (MR), which uses a linear iterative process to compute the scores of countries and products; this method share similarities with the famous algorithm PageRank [12-14]; (2) the fitnesscomplexity method (FCM), which uses a nonlinear iterative method to compute the fitness of countries and the complexity of products [1]. MR was shown to outperform previous indices based on governance, education, and other economic competitiveness factors $[15,16]$. However, MR 
fails in precisely evaluating the competitiveness of some special countries, such as India and China $[17,18]$. The fitness-complexity method is based on the fact that only competitive countries can produce high-quality products, while less competitive countries can only produce low-quality products. If a product is only produced by competitive countries, it is a high-quality product; otherwise it is a lowcomplexity product. FCM outperforms MR both in accuracy and efficiency $[8,19]$. The previous works mainly focused on how to accurately evaluate and predict the economic growth of countries. In this work, we use both methods to study how a country is influenced by the international and domestic economic recessions.

Based on state of the art MR and FCM methods, our paper explores the robustness of countries' competitiveness. Using the matrix perturbation theory, we propose a convenient analytical method to test the stability of the competitiveness of countries and complexity of products. Then the proposed method is applied to the international trade networks, and we show that FCM can not only evaluate the fitness of countries, but also precisely characterize the robustness of their competitiveness. On the other hand, the MR scores fail to assess the robustness of countries' competitiveness compared to FCM. According to the results, only a very small number of countries possess strong robustness against economic recessions. In order to increase its robustness, a country should improve its fitness, which is also equivalent to diversifying its products according to refs. [1,3,8]. Moreover, we also use our method to simulate the trade conflict between USA and China and predict that the trade conflict sharply decreases the fitness of China, whereas it seldom influences USA, revealing strong robustness of USA.

The paper is organized as follows. In Section 2, we briefly describe the method of reflection and the fitness-complexity method, and then we introduce our way to use perturbation method. In Section 3, we apply the proposed method to the international trade networks. Finally, the conclusion is given.

\section{Materials and Methods}

In the section, we first describe the country-product networks in Section 2.1 and then introduce the classical method of reflections and fitness-complexity method in Section 2.2. Finally we describe our method to test the robustness of countries' competitiveness in Section 2.3.

\subsection{Dataset Description of the Country-Product Networks.} The dataset we use ranges from 1962 to 2014 [2, 20-23]. We use a network representation, in which one kind of nodes is countries and the other kind is products. Edges can only connect country and a product, meaning that the network is bipartite. The products are indeed not considered individually: each exported product was assigned to a predefined category. The dataset has 263 countries (or zones) and 988 product categories. Besides, we neglect a very small fraction of categories that are ambiguous (aggregate categories). Note that in the rest of the work we use the word product for category of product.
For each country-product pair, we know the total export in US\$ of products of a country. In practice, a country may produce more or less of a product. In order to characterize whether a country is a competitive exporter of a product or not, we use the "Revealed Comparative Advantage" (RCA) to renormalize the weight of the country-product relations and only edges with weight greater than 1 are kept. The RCA is defined as

$$
R C A_{i \alpha}=\frac{e_{i \alpha} / \sum_{j} e_{j \alpha}}{\sum_{\beta} e_{i \beta} / \sum_{j \beta} e_{j \beta}}
$$

where $e_{i \alpha}$ is the export in US\$ of country $i$ for product $\alpha$. After processing the data, we obtain the weighted matrix of the country-product network, denoted by $M=\left(M_{i j}\right)_{N_{c} \times N_{p}}$, where $N_{c}$ and $N_{p}$ represent the number of countries and products, respectively, and $M_{i \alpha}=R C A_{i \alpha} . R C A_{i \alpha}$ determines the relative importance of an export for a country and compares it with its relative importance for other countries. In network, we defined the number of products exported by country $i$ as its degree $d_{i}$, and the number of times a product $\alpha$ is exported as $d_{\alpha}$. Note that in general only the adjacency matrix of the network is considered, but for perturbation theory it is indeed more suitable to use the weighted matrix.

\subsection{Methods of Reflections (MR) and Fitness-Complexity} (FCM). Method of reflections is a classical economic complexity index by Hidalgo and Hausmann $[3,24]$. This method defines a score or each country $\left\{d_{i}^{(n)}\right\}$ and a score for each product $\left\{u_{\alpha}^{(n)}\right\}$ in an iterative way,

$$
\begin{aligned}
& d_{i}^{(n)}=\frac{1}{d_{i}} \sum_{\alpha} M_{i \alpha} u_{\alpha}^{(n-1)}, \\
& u_{\alpha}^{(n)}=\frac{1}{u_{\alpha}} \sum_{i} M_{i \alpha} d_{i}^{(n-1)},
\end{aligned}
$$

where $d_{i}$ and $u_{\alpha}$ are the country degree and product degree, respectively. According to (2), with the increase of iterations, $\left\{d_{i}^{(n)}\right\}$ and $\left\{u_{\alpha}^{(n)}\right\}$ will asymptotically converge to a trivial fixed point for arbitrary initial $\left\{d_{i}^{(0)}\right\}$ and $\left\{u_{\alpha}^{(0)}\right\}[25,26]$. However, this problem is solved by defining the final country score as $\widetilde{d_{i}^{c}}=\left(d_{i}^{c}-\left\langle d_{i}^{c}\right\rangle\right) / \sigma_{d_{i}^{c}}$, where $\left\langle d_{i}^{c}\right\rangle$ and $\sigma_{d_{i}^{c}}$ represent the average and the standard deviation of the final score $d_{i}^{c}$. When $n \longrightarrow$ $+\infty$, the fixed point solution is equivalent to an approach using the eigenvectors of the matrix $M$ [26]. In practice, we use $n=2$, as different iterations have different interpretation. The initial conditions for $\left\{d_{i}^{(0)}\right\}$ and $\left\{u_{\alpha}^{(0)}\right\}$ are set as $\left\{d_{i}^{(0)}\right\}=d_{i}$ and $\left\{u_{\alpha}^{(0)}\right\}=u_{\alpha}$. The results of (2) agree with the assumption that complex products (or high-quality products) have high scores and tend to be produced by developed countries, while developing countries only produce some low-quality products. This can be used to evaluate the competitiveness and the economic growth of a country. The index of (2) outperforms the degree-based index [8]. 
Fitness-complexity method defines the country fitness $\left\{F_{i}\right\}$ and product complexity $\left\{Q_{\alpha}\right\}$ as the stationary point of the following nonlinear recursive process [1]:

$$
\begin{aligned}
\widetilde{F}_{i}^{(n)} & =\sum_{\alpha} M_{i \alpha} Q_{\alpha}^{(n-1)}, \\
\widetilde{Q}_{\alpha}^{(n)} & =\frac{1}{\sum_{i} M_{i \alpha}\left(1 / F_{i}^{(n-1)}\right)} .
\end{aligned}
$$

The scores are normalized after each step:

$$
\begin{gathered}
F_{i}^{(n)}=\frac{\widetilde{F}_{i}^{(n)}}{\left\langle\widetilde{F}_{i}^{(n)}\right\rangle}, \\
Q_{\alpha}^{(n)}=\frac{\widetilde{Q}_{\alpha}^{(n)}}{\left\langle\widetilde{Q}_{\alpha}^{(n)}\right\rangle},
\end{gathered}
$$

where $\langle\ldots\rangle$ is the average operation. The initial values of $F_{i}^{(0)}$ and $Q_{\alpha}^{(0)}$ do not influence the final stationary state except some particular singular points. Without loss of generality, the initial condition are set as $F_{i}^{(0)}=1$ and $Q_{\alpha}^{(0)}=1$. When we apply (3) to the country-product bipartite networks, developed countries and high-quality products are inclined to have high fitness, while developing countries and lowquality products tend to have small complexity. Therefore, FCM can evaluate the competitiveness of countries and the complexity of products $[1,25]$ and predict the future economic development $[19,27]$. This method has been successfully applied to other fields, such as ecological networks [28] and scientific competitiveness of nations [29].

Note that we use both MR and FCM to describe the "Economic Complexity Index" of countries or "Product Complexity Index" of products in the paper. In the following, we define the competitiveness as the "Economic Complexity Index" of both MR and FCM method. For MR method, the competitiveness is represented by $d_{i}$ in (2), while, for FCM method, the competitiveness is represented by the fitness $F_{i}^{(n)}$ in (4).

2.3. Robustness of the Countries' Competitiveness. In order to stimulate the economy, countries design various tariffs and other policies to promote or reduce the exports/imports of certain products. In theory, it would be possible to infer these changes based on an analysis of the matrix $M$. However, analyzing the detailed reason of the fluctuation of $M$ is prohibitive in practice. In the work, we investigate how the competitiveness of countries changes with perturbations of matrix $M$. Smaller fluctuations of the metrics mean higher robustness. This can reflect how resilient a country is to a change of policy. For the precise relationship between the exports and policies, please refer to [30-32].

In order to study the perturbation, we introduce a small number $\varepsilon$ and a perturbation matrix $B$. The resulting perturbed matrix is $M(\varepsilon)=M+\varepsilon B, \Delta M=\varepsilon B$. After the perturbation, the stationary points of (2) become $\bar{d}_{i}(\varepsilon)$ and $\bar{u}_{\alpha}(\varepsilon)$. A straightforward approach to obtain $\bar{d}_{i}(\varepsilon)$ and $\bar{u}_{\alpha}(\varepsilon)$ is recalculating (2) based on $M(\varepsilon)$. Here, we introduce a perturbation method to compute $\bar{d}_{i}(\varepsilon)$ and $\bar{u}_{\alpha}(\varepsilon)$, as well as the FCM scores. If you are not interested in the complex derivation procedure, please skip the following part, which does not influence the global comprehension of the paper.

We use Taylor's formalism $[33,34]$ to represent the perturbed quantities $\bar{d}_{i}(\varepsilon)$ and $\bar{u}_{\alpha}(\varepsilon)$; i.e., $\bar{d}_{i}(\varepsilon)=\bar{d}_{i}+$ $\sum_{k=1}^{+\infty} g_{i}^{(k)} \varepsilon^{k}$ and $\bar{u}_{\alpha}(\varepsilon)=\bar{u}_{\alpha}+\sum_{k=1}^{+\infty} h_{\alpha}^{(k)} \varepsilon^{k}$. When $\varepsilon=0, \bar{d}_{i}(\varepsilon)$ and $\bar{u}_{\alpha}(\varepsilon)$ reduce to $\bar{d}_{i}$ and $\bar{u}_{\alpha}$. Moreover, the degree $d_{i}$ and $u_{\alpha}$ change to $d_{i}(\varepsilon)=d_{i}+\varepsilon d_{B, i}$ and $u_{\alpha}(\varepsilon)=u_{\alpha}+\varepsilon u_{B, \alpha}$, where $d_{B, i}=\sum_{\alpha} B_{i \alpha}$ and $u_{B, \alpha}=\sum_{i} B_{i \alpha}$.

According to the perturbation theory $[34,35]$, by substituting the Taylor's formalism of each variable into (2) and keeping only the first order of $\varepsilon$, we obtain Taylor's decomposition of (2),

$$
\begin{aligned}
& g_{i}^{(1)} \varepsilon=-\frac{\varepsilon d_{B, i}}{\bar{d}_{i}^{2}} \sum_{\alpha} M_{i \alpha} \bar{u}_{\alpha}+\frac{\varepsilon}{d_{i}} \sum_{\alpha}\left(B_{i \alpha} \bar{u}_{\alpha}+M_{i \alpha} h_{\alpha}^{(1)}\right), \\
& h_{\alpha}^{(1)} \varepsilon=-\frac{\varepsilon u_{B, \alpha}}{\bar{u}_{\alpha}^{2}} \sum_{i} M_{i \alpha} \bar{d}_{\alpha}+\frac{\varepsilon}{u_{\alpha}} \sum_{i}\left(B_{i \alpha} \bar{d}_{i}+M_{i \alpha} g_{i}^{(1)}\right) .
\end{aligned}
$$

We denote $\mathbf{g}^{(1)}=\left[g_{i}^{(1)}\right]_{N_{c} \times 1}, \mathbf{h}^{(1)}=\left[h_{\alpha}^{(1)}\right]_{N_{p} \times 1}$, $\mathbf{C}_{1}(B)=\left[c_{i}(B)\right]_{N_{c} \times 1}, \mathbf{C}_{2}(B)=\left[c_{\alpha}(B)\right]_{N_{p} \times 1}$, where $c_{i}(B)=-\left(d_{B, i} / \bar{d}_{i}^{2}\right) \sum_{\alpha} M_{i \alpha} \bar{u}_{\alpha}+\left(1 / d_{i}\right) \sum_{\alpha} B_{i \alpha} \bar{u}_{\alpha}$ and $c_{\alpha}(B)=$ $-\left(u_{B, \alpha} / \bar{u}_{\alpha}^{2}\right) \sum_{i} M_{i \alpha} \bar{d}_{\alpha}+\left(1 / u_{\alpha}\right) \sum_{i} B_{i \alpha} \bar{d}_{i}$.

Equation (5) can be written in matrix formalism as

$$
\left[\begin{array}{l}
\mathbf{g}^{(1)} \\
\mathbf{h}^{(1)}
\end{array}\right]=\left[\begin{array}{l}
\mathbf{C}_{1}(B) \\
\mathbf{C}_{2}(B)
\end{array}\right]+\left[\begin{array}{c}
0, D_{1}^{-1} M \\
D_{2}^{-1} M^{T}, 0
\end{array}\right]\left[\begin{array}{l}
\mathbf{g}^{(1)} \\
\mathbf{h}^{(1)}
\end{array}\right],
$$

where $D_{1}=\operatorname{diag}\left\{d_{1}, d_{2}, \ldots, d_{N_{c}}\right\}$ and $D_{2}=$ $\operatorname{diag}\left\{u_{1}, u_{2}, \ldots, u_{N_{c}}\right\} . \mathbf{g}^{(1)}$ and $\mathbf{h}^{(1)}$ could be solved as

$$
\left[\begin{array}{l}
\mathbf{g}^{(1)} \\
\mathbf{h}^{(1)}
\end{array}\right]=\left(I-\left[\begin{array}{c}
0, D_{1}^{-1} M \\
D_{2}^{-1} M^{T}, 0
\end{array}\right]\right)^{-1}\left[\begin{array}{l}
\mathbf{C}_{1}(B) \\
\mathbf{C}_{2}(B)
\end{array}\right] .
$$

Equation (7) is used to compute the influence of the perturbation $\Delta M$ on the MR. Next we analyze the influence of $\Delta M=$ $\varepsilon B$ on FCM. Supposing that $\bar{F}_{i}(\varepsilon)$ and $\bar{Q}_{\alpha}(\varepsilon)$ are the stable point of the matrix $M^{\prime}=M+\Delta M$ and could be represented by Taylor's formalism; i.e., $\bar{F}_{i}(\varepsilon)=\bar{F}_{i}+\sum_{k=1}^{+\infty} f_{i}^{(k)} \varepsilon^{k}$ and $\bar{Q}_{\alpha}(\varepsilon)=\bar{Q}_{\alpha}+\sum_{k=1}^{+\infty} q_{\alpha}^{(k)} \varepsilon^{k}$. Following the procedure introduced above, we substitute Taylor's formalism of each variable into (3) and (4) and keep only the first order of $\varepsilon$,

$$
\begin{aligned}
f_{i}^{(1)} \varepsilon & =c_{1} \sum_{\alpha}\left(M_{i \alpha} q_{\alpha}^{(1)}+B_{i \alpha} \bar{Q}_{\alpha}\right) \varepsilon+c_{2} \varepsilon, \\
q_{\alpha}^{(1)} \varepsilon & =c_{3} \sum_{i}\left(-M_{i \alpha} \frac{1}{\bar{F}_{i}^{2}} f_{i}^{(1)}+B_{i \alpha} \frac{1}{\bar{F}_{i}}\right) \varepsilon+c_{4} \varepsilon,
\end{aligned}
$$

where $c_{1}=1 /\left\langle\widetilde{F}_{i}\right\rangle$ and $c_{3}=-\widetilde{Q}_{i}^{2} /\left\langle\widetilde{Q}_{i}\right\rangle$. $c_{2}=-\left(\widetilde{F}_{i} /\left\langle\widetilde{F}_{i}\right\rangle^{2}\right)\left\langle\sum_{\alpha}\left(M_{i \alpha} q_{\alpha}^{(1)}+B_{i \alpha} \bar{Q}_{\alpha}\right)\right\rangle$ and $c_{4}=$ $\left(\widetilde{Q}_{i} /\left\langle\widetilde{Q}_{i}\right\rangle^{2}\right)\left\langle\sum_{i}\left[\left(-M_{i \alpha}\left(1 / \bar{F}_{i}^{2}\right) f_{i}^{(1)}+B_{i \alpha}\left(1 / \bar{F}_{i}\right)\right) \widetilde{Q}_{i}^{2}\right]\right\rangle \quad$ are two parameters relevant to $i$ and $\alpha$, respectively, which 


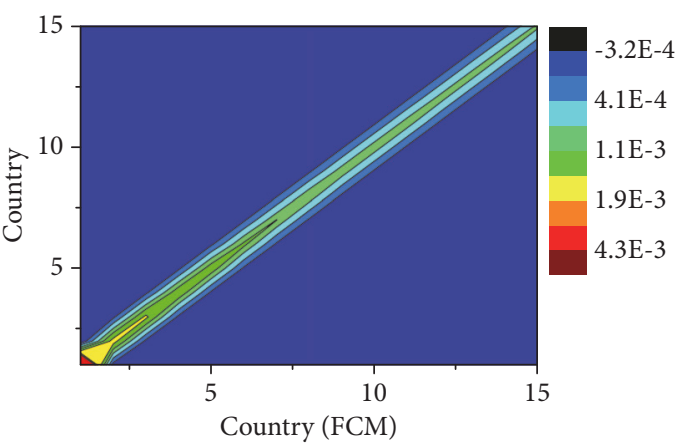

(a)

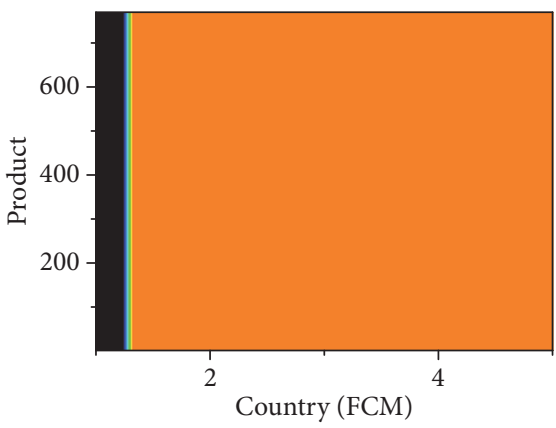

(c)

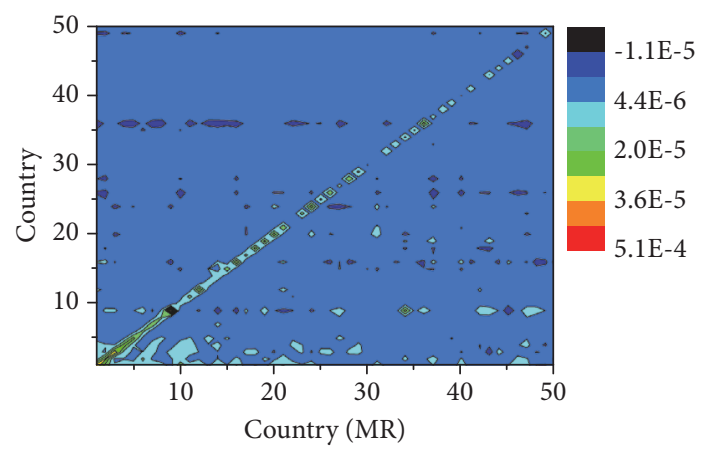

(b)

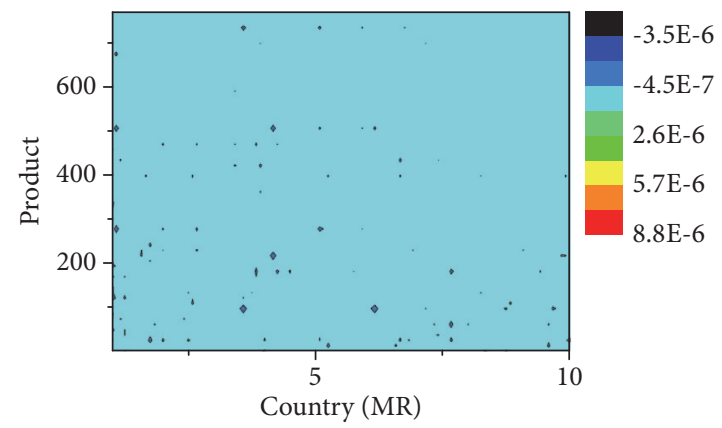

(d)

FIGURE 1: (Color online) The decrease of the counties and products scores induced by individually reducing the exports of countries by $5 \%$ for FCM and MR, as a function of the countries as rank in their respective method. (a) Change of the fitness scores (in FCM) of countries. (b) Change of the countries scores (in MR). (c) Change of the complexity (FCM) of products. (d) Change of the products scores (MR). Note that in the dataset, we have 263 countries (or zones) and 988 product categories. However, in the four panels, we only show the snapshot results of some competitive countries and complex product because the influence of other countries and products is much small.

guarantee the normalization of $\bar{F}_{i}(\varepsilon)$ and $\bar{Q}_{\alpha}(\varepsilon)$. Though $c_{2}$ and $c_{4}$ are function of $q_{\alpha}^{(1)}$ and $f_{i}^{(1)}$, we treat them as constants since they have average operations of the two variables when calculating $q_{\alpha}^{(1)}$ and $f_{i}^{(1)}$. Denote $\mathbf{f}^{(1)}=\left(f_{i}^{(1)}\right)_{N_{c} \times 1}$ and $\mathbf{q}^{(1)}=\left(q_{\alpha}^{(1)}\right)_{N_{p} \times 1}$. Similar to (7), the perturbation of FCM is

$$
\left[\begin{array}{l}
\mathbf{f}^{(1)} \\
\mathbf{q}^{(1)}
\end{array}\right]=\left(I-\left[\begin{array}{c}
0, c_{1} M \\
-c_{3} M^{T} D_{3}, 0
\end{array}\right]\right)^{-1}\left[\begin{array}{l}
\mathbf{C}_{3}(B) \\
\mathbf{C}_{4}(B)
\end{array}\right] .
$$

where $D_{3}=\operatorname{diag}\left\{1 / \bar{F}_{1}^{2}, \ldots, 1 / \bar{F}_{i}^{2}, \ldots, 1 / \bar{F}_{N_{c}}^{2}\right\}, \mathrm{C}_{3}(B)=$ $\left(c_{1} \sum_{\alpha} B_{i \alpha} \bar{Q}_{\alpha}+c_{2}\right)_{N_{c} \times 1}$, and $\mathbf{C}_{4}(B)=\left(c_{3} \sum_{i} B_{i \alpha}\left(1 / \bar{F}_{i}\right)+\right.$ $\left.c_{4}\right)_{N_{p} \times 1}$. Note that $c_{2}$ and $c_{4}$ seldom influence the analysis of $\mathbf{f}^{(1)}$ and $\mathbf{q}^{(1)}$, since the eigenvector corresponding to the largest eigenvalue of matrix $\left(I-\left[\begin{array}{c}0, c_{1} M \\ -c_{3} M^{T} D_{3}, 0\end{array}\right]\right)^{-1}$ actually represents the stationary point of the FCM. When analyzing the perturbation of the stationary point of FCM, we can ignore $c_{2}$ and $c_{4}$ for convenience.

$\mathbf{f}^{(1)}$ and $\mathbf{q}^{(1)}$ represent the fluctuation induced by a small perturbation in FCM. In the experiments, based on the proposed method, we will show how the competitiveness $\left(d_{i}\right.$ and $F_{i}^{(n)}$ ) of a country changes with different perturbations. Note that without (7) and (9), we can still obtain the results by recalculating (2) and (3) every time when $M$ changes.

\section{Results}

The exports of countries are influenced by a wide range of factors, and obtaining the precise influence of each factor is prohibitive. Instead, we perturb the country-product matrix $M$ following two different scenarios: (1) National recession: a country suffers from natural disasters (e.g., volcanic eruptions, tsunamis), unexpected crisis, or inner industrial problems. All its product exports are reduced by a fixed quantity. (2) Product reduction: the exports of a certain product are reduced for all exporting countries. For example, adverse weather happens, or the products (e.g., mobile phone, clothes) may be out of fashion and people change their tastes, which leads to the export decrease of a certain product. At last, we utilize the method to simulate the trade conflict between USA and China.

We first consider the case of national recession. Suppose that country $i$ is the targeted country and that the export of its products is reduced by $5 \%$. Then the elements of $\Delta M$ are $\Delta M_{k j}=-M_{k j} \times 5 \%(k=i)$ and $\Delta M_{k j}=0$ otherwise. The other changes (e.g., $1 \%, 4 \%$ ) of the edge weights do not influence the analysis. By substituting $B=\Delta M$ and $\varepsilon=1$ into (7) and (9), we obtain the changes of competitiveness of the country and the country's influence on other countries. Figure 1 shows the influence of the national recession case as a function of FCM and MR scores. In Figure 1(a), the decrease of fitness mainly occurs on the diagonal elements, implying 


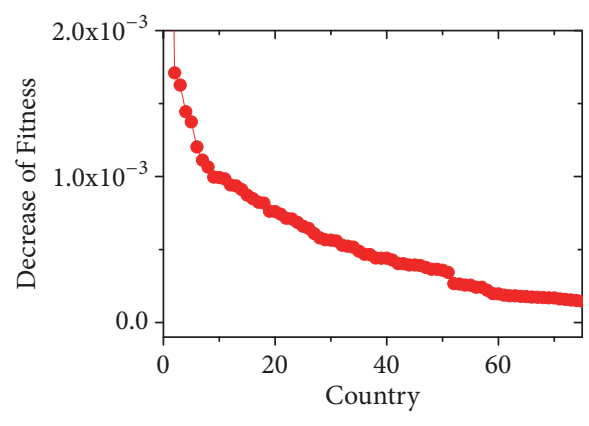

(a)

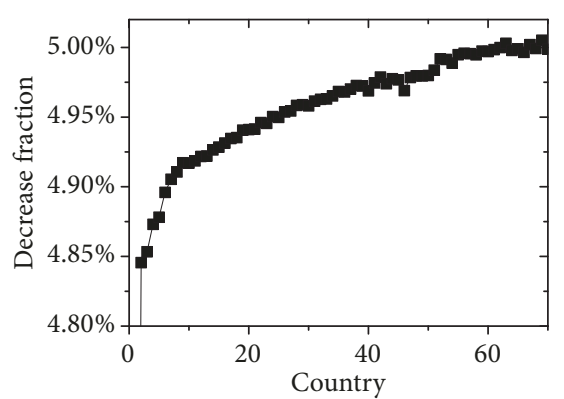

(b)

Figure 2: (Color online) The decrease of countries' fitness as a function of their rank for FCM. (a) Absolute decrease of countries' fitness. (b) Relative decrease of countries' fitness.

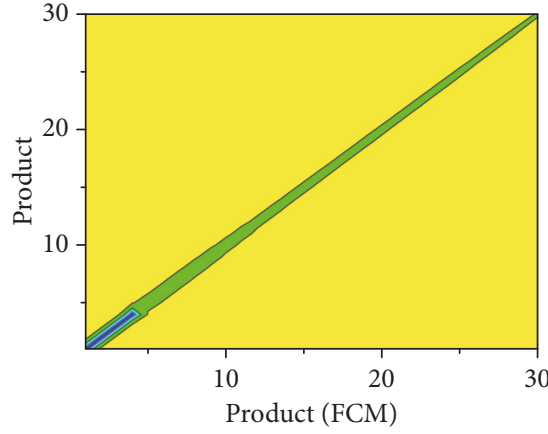

(a)

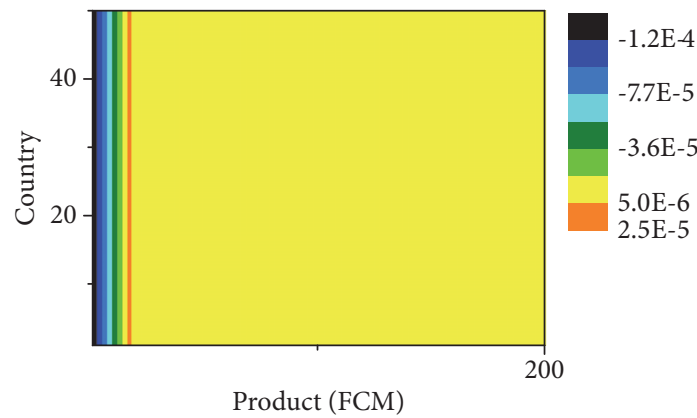

(c)

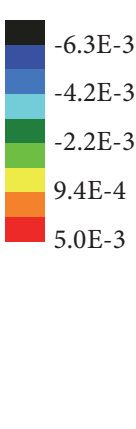

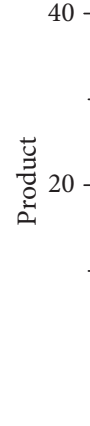
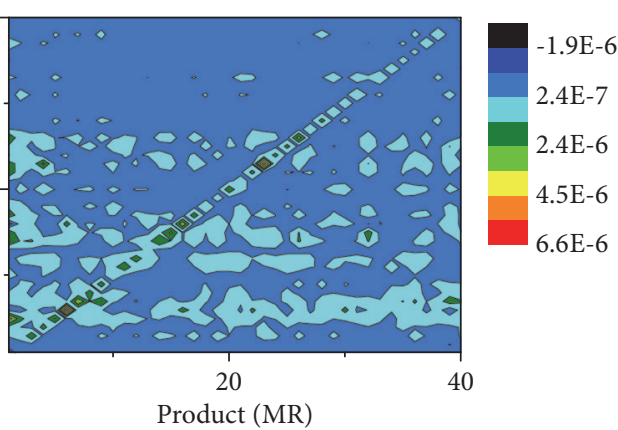

(b)

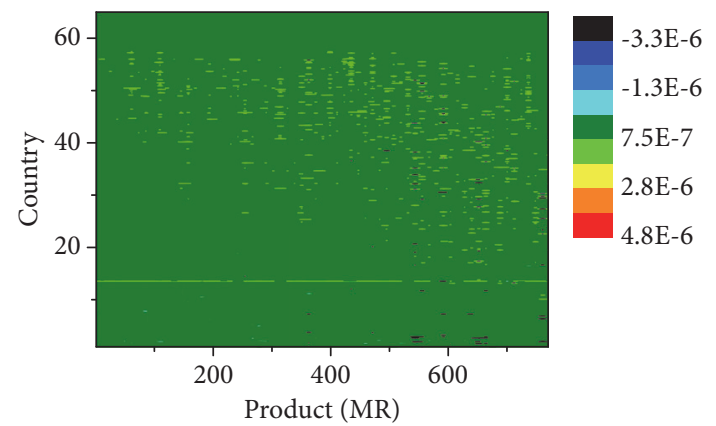

(d)

Figure 3: (Color online) The decrease of the counties and products scores induced by individually reducing the exports of products by $5 \%$ for FCM and MR, as a function of the countries and products rank in their respective method. (a) Change of the fitness scores (in FCM) of countries. (b) Change of the countries scores (in MR). (c) Change of the complexity (FCM) of products. (d) Change of the products scores (MR).

that the targeted countries influence other countries a little. Note that high fitness countries are well linked together and influence each other more that low fitness countries, whereas low high fitness countries seldom influence the other countries. Consequently, FCM index could be used to evaluate the robustness of countries; higher fitness means stronger robustness and is better. In Figure 1(b), the influence ordered by MR is chaotic, and, thus, the MR index cannot characterize the country robustness. Further, Figure 1(c) shows the influence of country recession on product complexity, where competitive countries exert big influence on the complexity of products, which is in accord with reality that the prices of various products are largely determined by the markets of developed countries. However, in Figure 1(d), the influence of MR is chaotic.

According to Figure 1, FCM is a perfect index to characterize the robustness of countries. Figure 2 shows the decrease of the countries' fitness when reducing the exports of themselves. We see that high fitness countries are sensitive to the decrease of their exports. Moreover, in Figure 2(b), the fitness decreases of countries have a positive correlation with their fitness, which further illustrates the effectiveness of FCM in characterizing the robustness of countries. Additionally, we also investigate the robustness based on MR. Similar to 


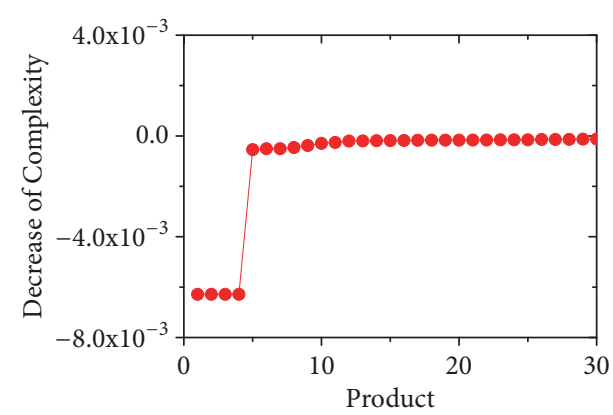

(a)

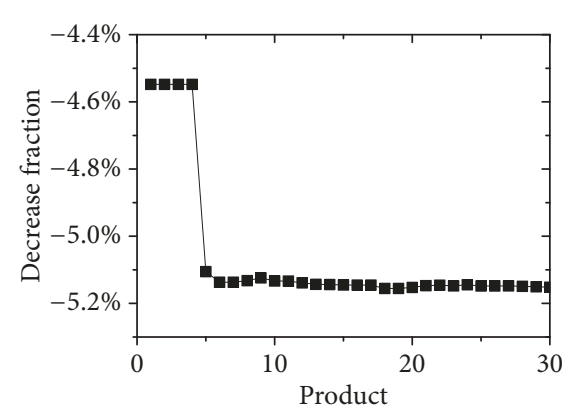

(b)

FIgURE 4: (Color online) The decrease of products' complexity as a function of their rank for FCM. (a) Absolute decrease of products' complexity. (b) Relative decrease of products' complexity.

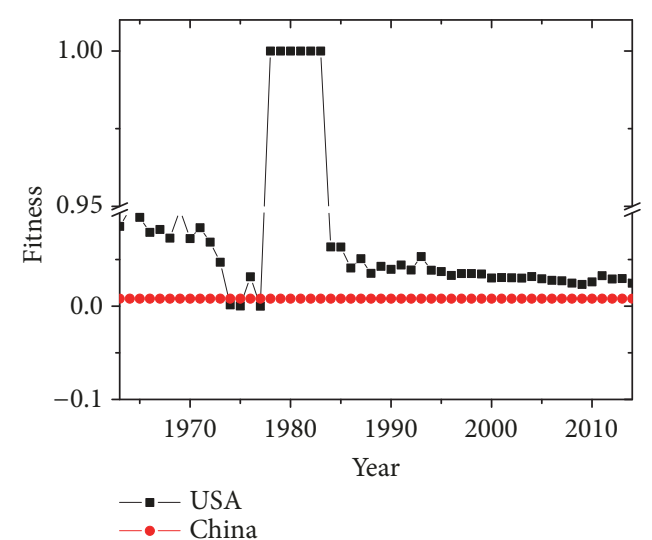

Figure 5: (Color online) The evolving paths of the fitness of USA and China range from 1962 to 2000. The fitness of the two countries is calculated every year.

Figures 2(a) and 2(b), the average decrease of country score is about $4.9 \%$.

Following the same method, we also analyze the influence of reduced products in Figure 3. Suppose that the targeted product reduces $5 \%$ weight of its connected edges, which means that all countries reduce $5 \%$ exports of the particular product. In Figure 3, FCM outperforms MR in characterizing the relationship between product score and the robustness, since the change of products' complexity mainly occurs on the diagonal elements. Note that decreasing the export volume of a certain product would increase its complexity, which agrees with the phenomenon "thing with rare be expensive". In order to better understand the complexity fluctuation, Figure 4 shows the decrease of the complexity as a function of the product perturbation. We see that the reduced exports of some high-quality products lead to a sharp increase of their complexity, while the complexity of lowquality products fluctuate a little (see Figure 4(a)). However, the relative fluctuations of high-quality products are very small in Figure 4(b), revealing that high-quality products have stronger robustness against the reduction of themselves than low-quality products. Note that the results of Figure 4 are in contrast with Figure 2. The recession of countries (products) will reduce (increase) their scores more than any other countries (products).

Next, we investigate which countries and which products have high scores and how the connection is between high fitness countries and high-quality products. Since MR cannot describe the robustness of the countries' competitiveness, we focus on the FCM case. In Table 1, we can see that the developed countries, such as USA, UK, and Germany, export not only high-quality products, but also some low-quality products including fish and accessories. China also exports some high-quality products and ranks high in fitness. The reason is that China exports some consumer electronics, such as electric cookers and washing machines, which are categorized into the same classes. Note that though Russia is considered as a developed country, its exports are mainly low-quality products and should be a developing country based on FCM. Moreover, we also show the export countries of products with different qualities in Table 2. In Table 2, competitive countries export products of diverse qualities, while less competitive countries only export low-quality products. Note that the robustness is positively correlated with the fitness in Figure 2. Though some developed countries have small product diversity, they have strong robustness against different economic failures.

At last, based on the robust theory of the paper, we simulate the current trade conflict between USA and China. Recently, the president Donald Trump of USA imposes high tariff on Chinese exports to force China renegotiating its trade balance with USA, while China opposes the policy and proposes the tit-for-tat tariff on American products. How to quantify the win and loss of the two countries is an open problem. Here, we simulate the fitness dynamics of the two countries. We first show the evolving paths of the fitness of USA and China range from 1962 to 2014, respectively, in Figure 5. In Figure 5, the fitness of China grows slowly, meaning the economic increase of China, whereas USA has large fluctuation between 1979 and 1986. This can be explained by several factors (e.g., political problems, cold war between the Soviet Union and USA) influencing the trades.

According to the public news, USA imposes high tariff on Chinese high-tech products that include aircraft, iron, and medical instruments [36]. China plans to improve the tariff on products such as soya beans or cars [37]. Until now, we 
TABLE 1: The main export products of some high fitness countries. The first column is the descending order of the countries by the fitness of countries in FCM. In the table, only the top-10 influential export products are listed here, where the products are ranked according to the product scores by FCM.

\begin{tabular}{|c|c|c|}
\hline $\begin{array}{l}\text { Fitness } \\
\text { Ranking }\end{array}$ & Country & Top-10 influential export products \\
\hline 1 & USA & $\begin{array}{l}\text { (1) Fuel oils. (2) Construction and mining machinery. (3) Non-ferrous base metal } \\
\text { waste and scrap. (4) Gasoline and other light oils. (5) Machinery for specialized } \\
\text { industries. (6) Parts and accessories of some special instruments. (7) Special } \\
\text { transactions and commodities. (8) Crude petroleum and oils from bituminous } \\
\text { materials. (9) Petroleum bitumen, petroleum coke and bituminous mixtures. (10) } \\
\text { Petroleum gases and other gaseous hydrocarbons. }\end{array}$ \\
\hline
\end{tabular}

(1) Crustaceans and molluscs, fresh, chilled, frozen, salted, etc. (2) Non-ferrous base metal waste and scrap. (3) Petroleum bitumen, petroleum coke and $2 \quad \mathrm{UK}$

bituminous mixtures. (4) Fish, dried, salted or in brine. (5) Crustaceans and molluscs, prepared or unprepared. (6) Coffee green, roasted. (7) Sheep and lamb skin without the wool. (8) Building and monumental (dimension) stone. (9) Fuel oils. (10) Petroleum gases and other gaseous hydrocarbons.

(1) Crude petroleum and oils from bituminous materials. (2) Parts and accessories of some special instruments. (3) Surveying, navigational, compasses, etc,

3 Germany instruments. (4) Crustaceans and molluscs, fresh, chilled, frozen, salted, etc. (5) Coffee green, roasted. (6) Non-ferrous metal waste and scrap. (7) Fuel oils. (8) Petroleum gases and other gaseous hydrocarbons. (9) Fuel oils. (10) Diamonds (non-industrial).

(1) Castor oil seeds. (2) True hemp, raw or processed but not spun. (3) Coal gas, water gas and similar gases. (4) Potassium salts, natural, crude. (5) Iron pyrites, unroasted. (6) Roasted iron pyrites. (7) Ores and concentrates of uranium and thorium. (8) Vegetable textile fibres and waste. (9) Rye, unmilled. (10) Mate.

(1) Non-ferrous base metal waste and scrap. (2) Crude petroleum and oils from bituminous materials. (3) Fuel oils. (4) Construction and mining machinery. (5) Parts of some special machinery and equipment. (6) Machinery for specialized $7 \quad$ China industries. (7) Passenger motor vehicles. (8) Trailers and transports containers. (9) Surveying, navigational, compasses, etc, instruments. (10) Special transactions and commodities.

(1) Coffee green, roasted. (2) Petroleum gases. (3) Building and monumental (dimension) stone. (4) Crude petroleum and oils from bituminous materials. (5) Fish, frozen, excluding fillets. (6) Fish fillets, frozen. (7) Fish, dried, salted or in brine. (8) Crustaceans and molluscs. (9) Non-ferrous metal waste and scrap. (10) Fuel oils.

cannot obtain the data to compute the volumes of the reduced exports induced by the trade conflict. However, we can simulate the influence based on historical dataset. Figure 6 shows the increases of different products for USA and China covering from the year 1962 to 2014. The original dataset only gives the product categories, not the export details of each product. In the simulation, we treat all categories that contain the key words, such as "iron" and "medical", as the corresponding products. In Figure 6, most of the exports increase on the whole except the soya beans. Due to enormous inner demands and restricted natural resource, China reduces its export of soya beans from 1989. Integrating Figures 5 and 6 , we find that the exports of the two countries increase on the whole.

Next, we artificially introduce some perturbation into the exports of the two countries. Following the tariff policies of the two countries, we suppose that the soya bean export of USA reduces $5 \%$ and the iron export of China reduces $5 \%$ for every year between 1975 and 2014. Here, we do not start from the year 1962, because that USA and China established diplomatic relations in the year 1972. Before 1972, China did not integrate into the global economics completely and the two countries had little trade connection. Thus, we start the simulation from 1975 to avoid noisy fluctuations. According to our proposed method (9), we obtain the fluctuation of the fitness of the two countries in Figure 7. If we reduce 5\% of the American soya beans and of the Chinese Iron steels, China will suffer more decrease of the fitness in Figure 7(a).

Next, we simulate another case. The aim of American policy is to reduce the growth of China, especially high-tech products. If USA does not start the conflict, supposing that the high-tech aircraft of China increases by $5 \%$, Figure 7(b) shows the increase of the fitness of the two countries. We find that the export increase of aircraft would improve the fitness of China much, whereas the fitness of USA would decrease only a little. Besides, we also simulate the perturbation of other high-tech products, such as industrial equipment and medical instruments, and the results are similar with Figure 7. Thus, we can predict that the trade conflict between the two countries would hurt China severely. However, USA 
TABLE 2: The main export countries of some products. The first column is the descending order of the products by the score $Q_{i}$ of FCM. In the table, the countries are ranked according to the country scores of FCM.

\begin{tabular}{|c|c|c|}
\hline $\begin{array}{l}\text { Product } \\
\text { Ranking }\end{array}$ & Product & Top-10 influential export countries \\
\hline 1 & Wood-based panels & $\begin{array}{l}\text { (1) China. (2) USA. (3) Spain. (4) France. (5) India. (6) UK. (7) } \\
\text { Venezuela. (8) Brazil. (9) Canada. (10) Germany. }\end{array}$ \\
\hline 2 & Castor oil seeds & $\begin{array}{l}\text { (1) China. (2) USA. (3) Spain. (4) France. (5) India. (6) UK. (7) } \\
\text { Venezuela. (8) Brazil. (9) Canada. (10) Germany. }\end{array}$ \\
\hline 3 & Coal gas, water gas and similar gases & $\begin{array}{l}\text { (1) USA. (2) Oman. (3) UK. (4) Brazil. (5) China. (6) Ecuador. } \\
\text { (7) Dominican Rp. (8) Algeria. (9) France. (10)Germany. }\end{array}$ \\
\hline 4 & Copra & $\begin{array}{l}\text { (1) China. (2) France. (3) Morocco. (4) Tunisia. (5) USA. (6) } \\
\text { Iran. (7) Italy. (8) Kazakhstan. (9) Pakistan. (10)Venezuela. }\end{array}$ \\
\hline 5 & Manila hemp, raw or processed but not spun & $\begin{array}{l}\text { (1) China. (2) Canada. (3) Germany. (4) Belgium-Lux. (5) } \\
\text { France. (6) Netherlands. (7) USA. (8) Austria. (9) Spain. } \\
\text { (10)Australia. }\end{array}$ \\
\hline 766 & $\begin{array}{c}\text { Parts of and accessories for apparatus } \\
\text { electrical instruments }\end{array}$ & $\begin{array}{l}\text { (1) USA. (2) UK. (3) France. (4) Germany. (5) Spain. (6) } \\
\text { Belgium-Lux. (7) Netherlands. (8) China. (9) Italy. (10)Brazil. }\end{array}$ \\
\hline 767 & Non-ferrous base metal waste and scrap & $\begin{array}{l}\text { (1) China. (2) France. (3) USA. (4) Brazil. (5) Australia. (6) } \\
\text { Austria. (7) Belgium-Lux. (8) Germany. (9) India. (10)Morocco. }\end{array}$ \\
\hline 768 & Machinery for specialized industries & $\begin{array}{l}\text { (1) China. (2) France. (3) USA. (4) Brazil. (5) Australia. (6) } \\
\text { Austria. (7) Belgium-Lux. (8) Germany. (9) India. (10)Morocco. }\end{array}$ \\
\hline 769 & Special transactions and commodities & $\begin{array}{l}\text { (1) China. (2) France. (3) USA. (4) Brazil. (5) Australia. (6) } \\
\text { Austria. (7) Belgium-Lux. (8) Germany. (9) India. (10)Morocco. }\end{array}$ \\
\hline 770 & $\begin{array}{c}\text { Postal packages not classified into other } \\
\text { classes }\end{array}$ & $\begin{array}{l}\text { (1) Algeria. (2) Angola. (3) Argentina. (4) Australia. (5) Austria. } \\
\text { (6) Belgium-Lux. (7) Brazil. (8) Bulgaria. (9) Canada. (10)Chile. }\end{array}$ \\
\hline
\end{tabular}

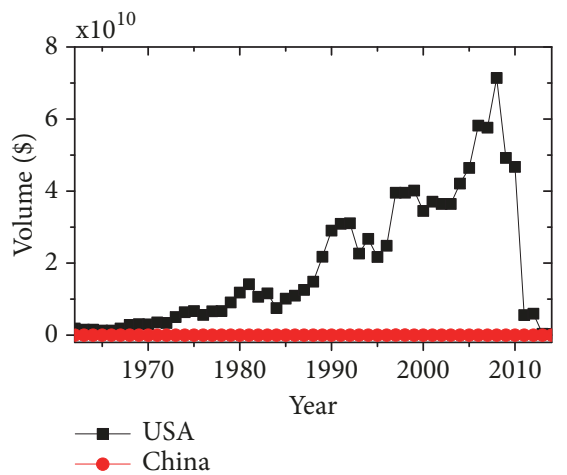

(a) Aircraft

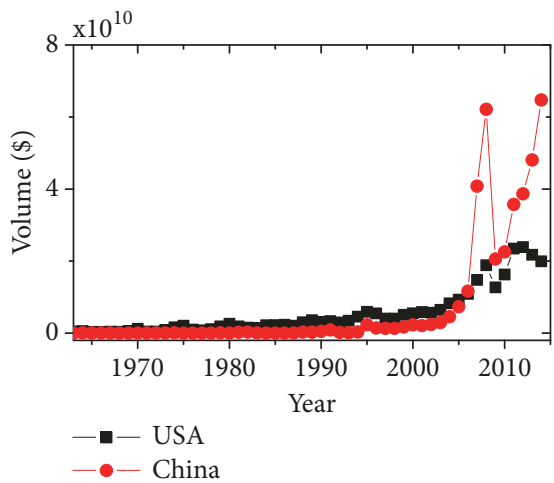

(c) Iron

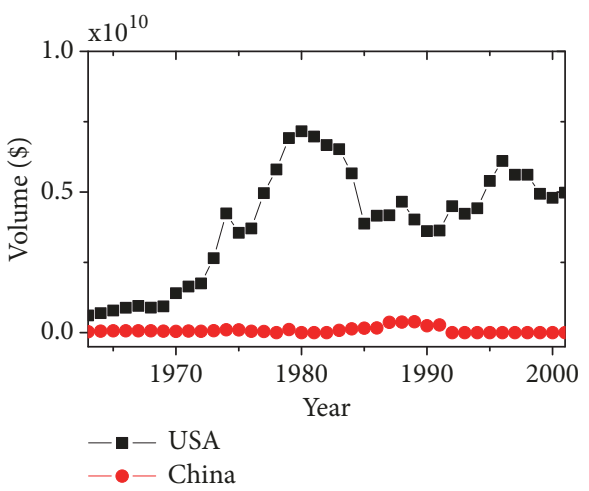

(b) Soya beans

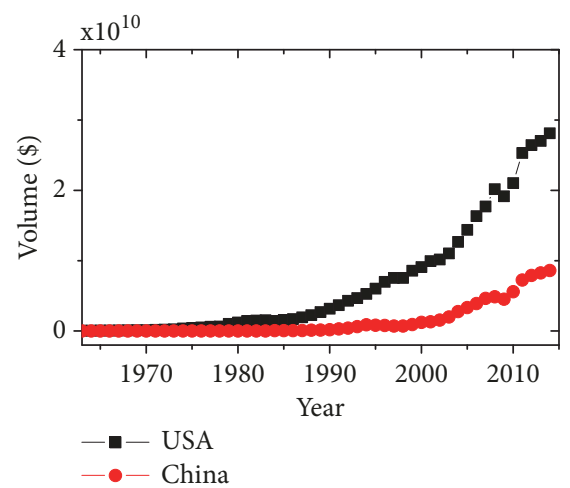

(d) Medical

FIGURE 6: (Color online) The increase of different product exports (in US dollars) for USA and China from 1962 to 2000. (a) Aircraft. (b) Soya beans. (c) Iron steels. (d) Medical instruments. 


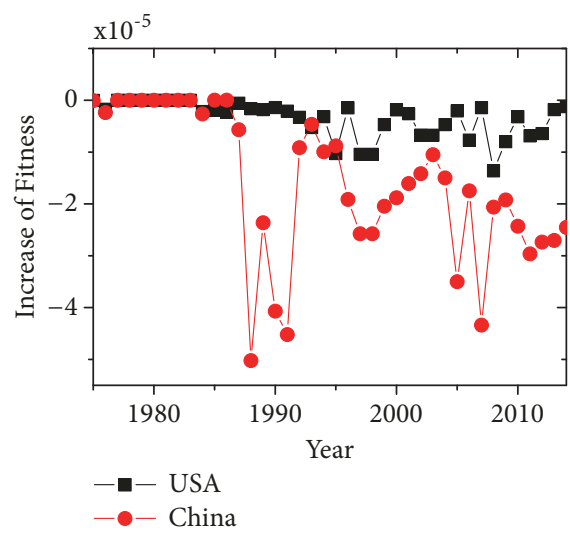

(a)

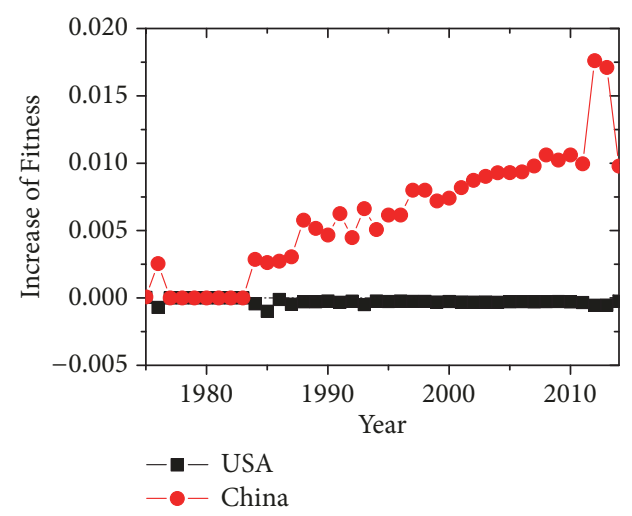

(b)

FIGURE 7: (Color online) Fluctuation of the fitness scores of USA and China. (a) The decrease of the fitness of USA and China by reducing 5\% of the American soya beans and of the Chinese Iron steels. (b) The increase of the fitness by increasing $5 \%$ of the export of Chinese aircraft. Note that we do not simulate the performance before the year 1975, because that USA and China established diplomatic relations in the year 1972. After 1972, China built diplomatic relations with many western countries and started to integrate into the global economics. Thus, we start the experiments from 1975 to avoid noisy fluctuations.

benefits only a little from the conflict. Note that, in the analysis, we do not consider the decrease of the American exports induced by the increase of the Chinese corresponding exports. China may take away some market shares of some high-tech products, which is beyond the scope of the paper.

\section{Conclusion}

In summary, we propose an analytical approach to calculate the robustness of the MR and FCM. The robustness of both methods is tested using perturbation theory. This analysis shows that the FCM is more resilient to perturbation, as the propagation between countries is less important than in MR. Moreover, we use our method to simulate the trade conflict between USA and China using FCM. The simulation results show that China will lose much competitiveness, whereas USA will get a small benefit from the conflict. Therefore, our work could supply additional information that organizations could benefit by taking the competitiveness robustness of countries into accounts. Since the robustness analysis is based on the artificial simulation, the inner relationships between countries (products) are not considered in the analysis. Consequently, the fluctuation of real economics may be different from the results in the paper. Detailed perturbation of real economic data could be integrated into the method to enhance the accuracy in the future.

\section{Data Availability}

The data used to support the findings of this study are available in the dataset collection of [20].

\section{Conflicts of Interest}

The authors declare no competing financial interests.

\section{Acknowledgments}

This work was jointly supported by the National Natural Science Foundation of China (nos. 61703281, 11547040, 61803266, and 61873171), the Ph.D. Start-Up Fund of Natural Science Foundation of Guangdong Province, China (nos. 2017A030310374 and 2016A030313036), the Science and Technology Innovation Commission of Shenzhen (no. JCYJ20160520162743717), Shenzhen Science and Technology Foundation (nos. JCYJ20150529164656096 and JCYJ20170302153955969), Guangdong Pre-National Project (2014GKXM054), Guangdong Province Key Laboratory of Popular High Performance Computers (2017B030314073), Foundation for Distinguished Young Talents in Higher Education of Guangdong (2015KONCX143), and the Young Teachers Start-Up Fund of Natural Science Foundation of Shenzhen University.

\section{References}

[1] A. Tacchella, M. Cristelli, G. Caldarelli, A. Gabrielli, and L. Pietronero, "A new metrics for countries' fitness and products' complexity," Scientific Reports, vol. 2, article 723, 2012.

[2] C. A. Hidalgo, B. Winger, A.-L. Barabási, and R. Hausmann, "The product space conditions the development of nations," Science, vol. 317, no. 5837, pp. 482-487, 2007.

[3] C. A. Hidalgo and R. Hausmann, "The building blocks of economic complexity," Proceedings of the National Acadamy of Sciences of the United States of America, vol. 106, no. 26, pp. 10570-10575, 2009.

[4] H. Liao, M. S. Mariani, M. Medo, Y.-C. Zhang, and M.-Y. Zhou, "Ranking in evolving complex networks," Physics Reports, vol. 689, pp. 1-54, 2017.

[5] G. M. Grossman and E. Helpman, "Quality Ladders in the Theory of Growth," The Review of Economic Studies, vol. 58, no. 1, p. 43, 1991. 
[6] D. Greenaway, International trade policy: From tariffs to the new protectionism, Macmillan, London, UK, 1983.

[7] H. Liepmann, Tariff Levels and The Economic Unity of Europe: An Examination of Tariff Policy, Export Movements and The Economic Integration of Europe, vol. 25, Routledge, 2017.

[8] M. S. Mariani, A. Vidmer, M. Medo, and Y.-C. Zhang, "Measuring economic complexity of countries and products: which metric to use?" The European Physical Journal B, vol. 88, no. 11, article 293, pp. 1-9, 2015.

[9] C. Kao, W.-Y. Wu, W.-J. Hsieh, T.-Y. Wang, C. Lin, and L.-H. Chen, "Measuring the national competitiveness of Southeast Asian countries," European Journal of Operational Research, vol. 187, no. 2, pp. 613-628, 2008.

[10] E. Siggel, "International competitiveness and comparative advantage: A survey and a proposal for measurement," Journal of Industry, Competition and Trade, vol. 6, no. 2, pp. 137-159, 2006.

[11] C. Antonelli, Handbook on the Economic Complexity of Technological Change, Edward Elgar Publishing, 2011.

[12] S. Brin, "The anatomy of a large-scale hypertextual Web search engine," Computer Networks, vol. 30, no. 1, pp. 107-117, 1998.

[13] L. Page, S. Brin, R. Motwani, and T. Winograd, “The pagerank citation ranking: Bringing order to the web," Tech. Rep., Stanford InfoLab, 1999.

[14] S. Albeaik, M. Kaltenberg, M. Alsaleh, and C. A. Hidalgo, "729 new measures of economic complexity (addendum to improving the economic complexity index)," 2017, https://arxiv.org/ abs/1708.04107.

[15] J. Felipe, U. Kumar, A. Abdon, and M. Bacate, "Product complexity and economic development," Structural Change and Economic Dynamics, vol. 23, no. 1, pp. 36-68, 2012.

[16] S. Poncet and F. Starosta de Waldemar, "Export upgrading and growth: The prerequisite of domestic embeddedness," World Development, vol. 51, pp. 1-15, 2013.

[17] A. Tacchella, M. Cristelli, G. Caldarelli, A. Gabrielli, and L. Pietronero, "Economic complexity: conceptual grounding of a new metrics for global competitiveness," Journal of Economic Dynamics \& Control, vol. 37, no. 8, pp. 1683-1691, 2013.

[18] F. Battiston, M. Cristelli, A. Tacchella, and L. Pietronero, "How metrics for economic complexity are affected by noise," Complexity Economics, vol. 3, no. 1, pp. 1-22, 2014.

[19] H. Liao and A. Vidmer, "A comparative analysis of the predictive abilities of economic complexity metrics using international trade network," Complexity, vol. 2018, Article ID 2825948, 12 pages, 2018.

[20] A. Simoes et al., “Country-Product Dataset," https://atlas.media .mit.edu/en/resources/data/.

[21] R. Feenstra, R. Lipsey, H. Deng, A. Ma, and H. Mo, "World Trade Flows: 1962-2000," National Bureau of Economic Research, 2005.

[22] R. Hausmann, J. Hwang, and D. Rodrik, "What you export matters," Journal of Economic Growth, vol. 12, no. 1, pp. 1-25, 2007.

[23] G. Gaulier and S. Zignago, Baci: International Trade Database at The Product-Level (The 1994-2007 Version), 2010.

[24] R. Hausmann, C. A. Hidalgo, S. Bustos, M. Coscia, A. Simoes, and M. A. Yildirim, The Atlas of Economic Complexity: Mapping Paths to Prosperity, Mit Press, 2014.

[25] M. Cristelli, A. Gabrielli, A. Tacchella, G. Caldarelli, and L. Pietronero, "Measuring the intangibles: A metrics for the economic complexity of countries and products," PloS One, vol. 8, no. 8, Article ID e70726, 2013.

[26] G. Caldarelli, M. Cristelli, A. Gabrielli, L. Pietronero, A. Scala, and A. Tacchella, "A network analysis of countries' export flows: firm grounds for the building blocks of the economy," PLoS ONE, vol. 7, no. 10, Article ID e47278, 2012.

[27] M. Cristelli, A. Tacchella, and L. Pietronero, "The heterogeneous dynamics of economic complexity," PLoS ONE, vol. 10, no. 2, Article ID e0117174, 2015.

[28] V. Domínguez-García and M. A. Muñoz, "Ranking species in mutualistic networks," Scientific Reports, vol. 5, article 8182, 2015.

[29] G. Cimini, A. Gabrielli, and F. S. Labini, "The scientific competitiveness of nations," PLoS ONE, vol. 9, no. 12, 2014.

[30] D. Hausman, M. McPherson, and D. Satz, Economic analysis, moral philosophy, and public policy, Cambridge University Press, 2018.

[31] R. G. Ehrenberg, R. S. Smith et al., Modern labor economics: Theory and public policy, Routledge, 2016.

[32] S. A. Marglin, Public Investment Criteria (Routledge Revivals): Benefit-Cost Analysis for Planned Economic Growth, Routledge, 2014.

[33] M. Nørgaard, N. K. Poulsen, and O. Ravn, "New developments in state estimation for nonlinear systems," Automatica, vol. 36, no. 11, pp. 1627-1638, 2000.

[34] T. Kato, Perturbation Theory for Linear Operators, vol. 132, Springer Science \& Business Media, 2013.

[35] W. G. Stewart, Matrix Perturbation Theory, 1990.

[36] https://zh.scribd.com/document/375467984/Trump-Chinatrade-targets\#from_embed.

[37] https://www.usatoday.com/story/money/business/2018/04/04/ full-list-us-products-china-planning-hittariffs/485071002/. 


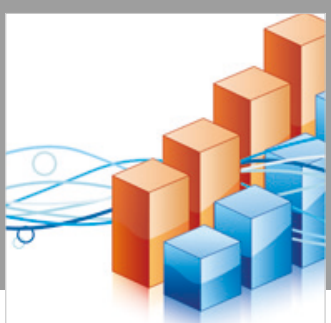

Advances in

Operations Research

\section{-n-m}
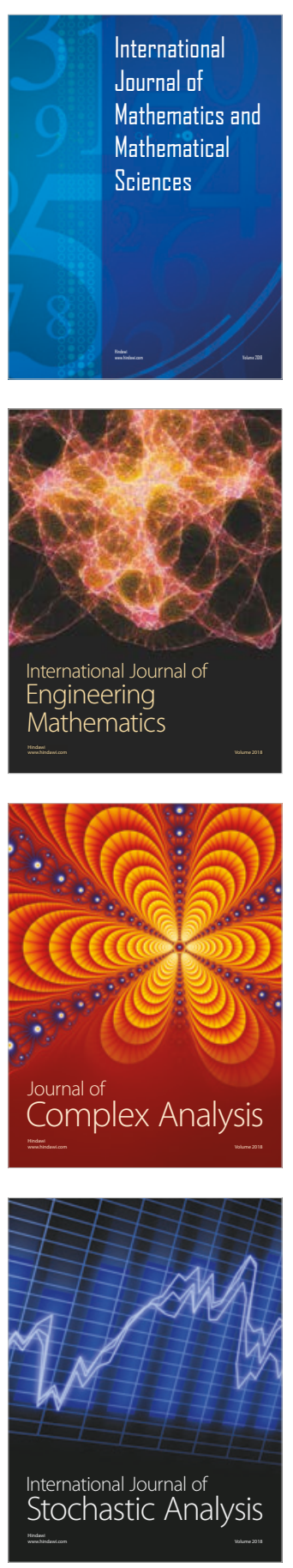
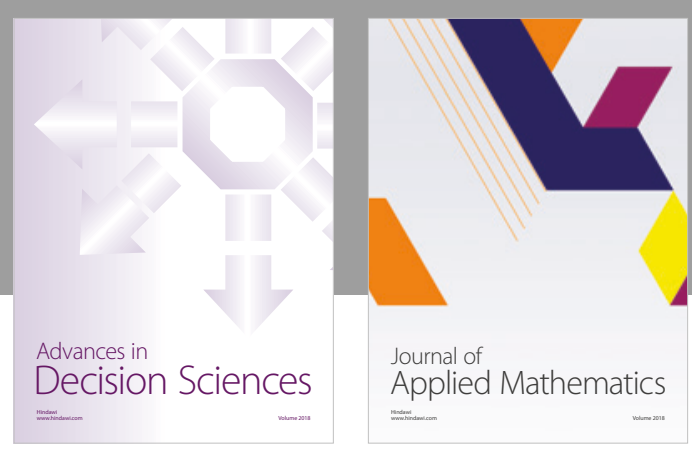

Journal of

Applied Mathematics
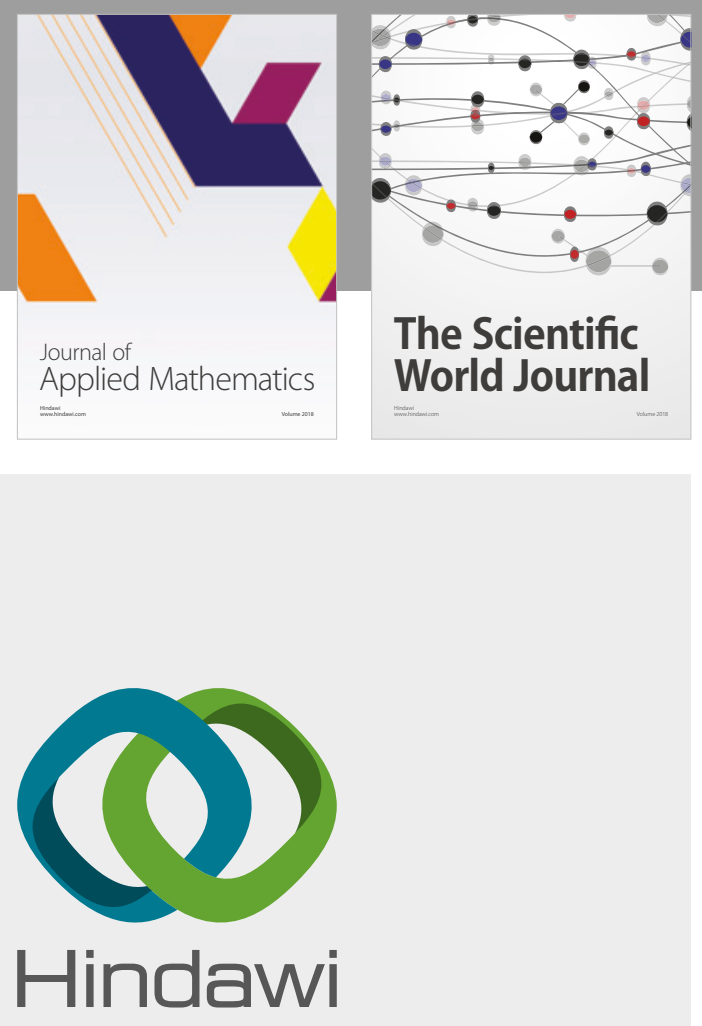

Submit your manuscripts at

www.hindawi.com

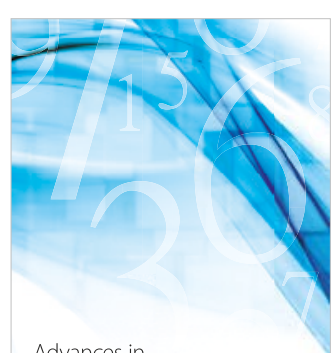

Advances in
Numerical Analysis
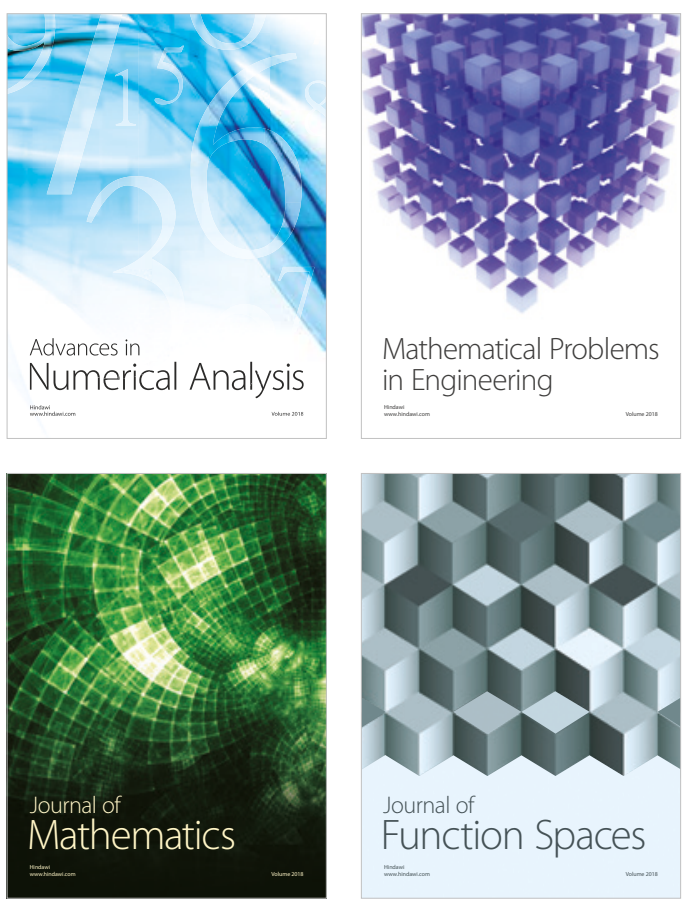

Mathematical Problems in Engineering

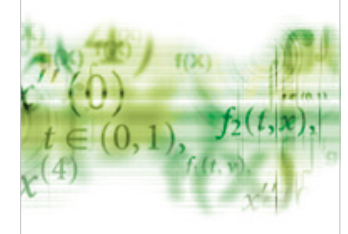

International Journal of

Differential Equations

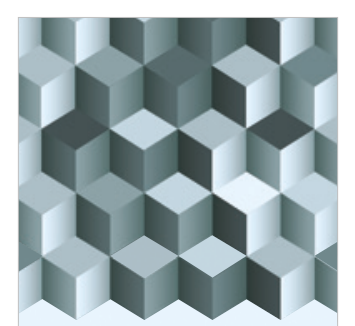

Journal of

Function Spaces
The Scientific

World Journal

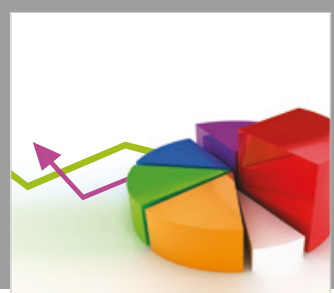

Journal of

Probability and Statistics
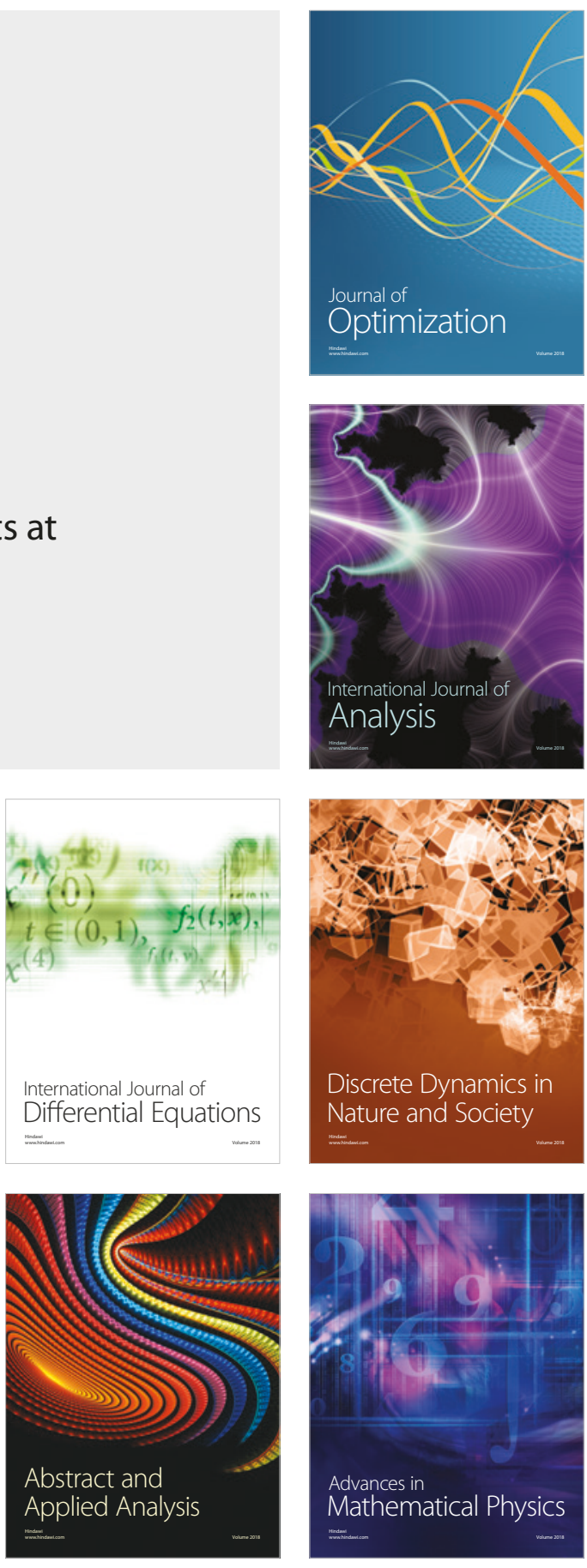